DOI: doi.org/10.21009/IJLECR.061.11

Received: 12 May 2020

Revised: 11 June 2020

Accepted: 18 June 2020

Published: 30 June 2020

\title{
INITIATING FLIPPED CLASSROOM INFORMING THE 4C SKILLS AMONG ENGLISH EDUCATION STUDENTS
}

\author{
Nia Kurniawati ${ }^{1, a)}$ \\ Universitas Suryakancana ${ }^{1)}$ \\ garyadinia2011@gmail.com ${ }^{\text {a) }}$
}

\begin{abstract}
Flipped classroom enables students to learn new content online by watching video lectures outside the classroom independently, with teachers offering more personalized guidance and interaction with students. This study tried to depict an effort of initiating flipped classroom to form the 4Cs among the English Student-Teachers. This study aimed to portray the process of initiating flipped classrooms, the obstacles, and the students' 4Cs reflection in the flipped classroom. The study involved four lecturers as collaborators in the lesson study of an English Teaching Media subject. The instruments used were observation, interview, and document analysis. In conducting the flipped class, Schoology was utilized. The results showed that, in initiating a flipped class, the lecturers should be creative in creating the video lectures and other classroom activities as a preclusion to boredom. Besides, the results also denoted the emerging capacity of the students' 4Cs during online and offline classes. Moreover, the lecturers considered flipped classrooms as a breakthrough that enables them to have a closer look at the students individually. Nonetheless, the flipped classroom's newness brings about intricacy since the lecturers should be able to manage online and offline classes simultaneously.
\end{abstract}

Keywords: Flipped classroom, Schoology, the 4Cs, lesson study, Preservice Teachers.

This study explores the flipped classroom's initiation with the aid of Schoology as the Learning Management System to form the 4Cs (Critical thinking, Communication, Collaboration, and Creativity) among the English Student-Teachers. Initiating the flipped classroom is required in this new digital era. The primacy of implementing the flipped classroom is set off by the notion that transformation to adopt new ways of learning that meet the conceptual needs of our time is increasingly required (O'Flaherty \& Phillips, 2015).

Online classes in the flipped classroom can also be a way to provide the preferred learning of students in this generation as they are accustomed to online stuff. If their preferred ways of learning can be fulfilled, students' ease of learning will be attained. Besides, $4 \mathrm{C}$ learning skills also show their significance in attending what is demanded in the new digital era. However, such skills are yet necessary to be developed for addressing shortages of skills among students. Hence, 4Cs by initiating the flipped classroom is substantial to be researched.

The 4Cs (critical thinking, communication, collaboration, and creativity) are required by the current education goal of Industrial Revolution 4.0 commended by many Indonesian educators lately. These are also concerned with 21 st-century skills or competencies, critical components of college and career readiness (Bialik \& Fadel, 2015; Soland, Hamilton, \& Stecher, 2013). It is 
stated that school systems are now dealing with the increase of pressure to bear graduates possessing this range of competencies (Soland et al., 2013). The skills are also often linked to the success of students in facing the ever-changing world. Having students master these skills helps them prepare for the increasing intricacy of 21 st- century life and work environments. To provide an understanding of what they are precise, the following is presented to unravel the 4Cs in detail.

Critical thinking is commonly signified by the ability to bear reasonably sound ideas. This ability can be built by some elements comprising deductive and inductive reasoning to solicit relevant information, decision making, and problem-solving (Bialik \& Fadel, 2015; Dede, 2010). The characteristics of students capable of thinking critically encompass the use of inductive and deductive reasoning, the collection of relevant information, the elicitation of essential questions clarifying point of view, and resulting in problem-solving, informed decision making, and the provision of reliable choices as the alternatives. Critical thinkers are 'likelier to be self-sufficient and therefore, less of a drain on state resources' (Facione, 1998, in Soland et al., 2013).

Communication deals with the ability to convey ideas that are as effective and efficient as possible. In this regard, the characteristics of communication-owning students are indicated by clear expressed thoughts, firm opinions, and stances, coherent instructions, influential s peech to motivate others, make effective use of digital media and environments in support or individual group works, and, to follow Dede (2010), the use of media on behalf of making given opinions precisely clear to different individuals. Moreover, in terms of I.C.T. use, it is characterized by information transmission in which the meaning becomes a useful expression for others (van Laar, et al., 2017).

As for the next skill of the century, collaboration constitutes students' cooperation within a group to pursue the given, shared goals. This skill is required in the 21 st century, for people can barely finish tasks without any help from others, whose problems are multifaceted. Therefore, to attain the skills, working together, working effectively within different groups, member compromises, taking responsibility as a team member dealing with specific tasks are the manifestations of collaboration. Therefore, the contribution given in collaboration is not only for one's achievement but also for others as mutualism is emphasized (Dede, 2010; van Laar, et al., 2017).

Last but not least, is creativity, denoting students' ability to make something new and novel inventions. The inventions are limited to some objects and include out-of-the-box ideas (Dede, 2010). It is listed as the essential leadership quality required to face increasing complexity and uncertainty of the world today (Bialik \& Fadel, 2015). It is further affirmed that creative students may have unique abilities in idea production, fluency, flexibility, and originality. In the classroom, creativity can be categorized into five levels, including imitation, variation, combination, transformation, and original creation as its apex.

In line with the $4 \mathrm{Cs}$, the demand for the flipped classroom is apparent corre spondingly. Flipped classroom enables students to learn new content online before and outside of the classroom with teachers offering more personalized guidance and interaction with students, instead of lecturing. It is carried out by turning over the activities in the classroom to online and offline classes. It usually begins with carrying out an online class preceding the offline class, which is then likely to be followed by another non-compulsory online classroom. Vaughan (2014) mentions that what is delivered to students in a flipped classroom is done outside of the classroom using taped lectures, videos, or other technology. The advantages of the flipped classroom are associated with students' engagement where students have ample time to inquire about facts and information from the online learning materials, teacher professional development on the awareness of instructional strategies (ibid.), and improved student achievement in their academic performance (O'Flaherty \& Phillips, 2015). 
Implementing the flipped classroom enables students to learn at their own pace, encourage ownership over their learning (Basal, 2015), and allow teachers to explore a multitude of instructional strategies in their free class time (Vaughan, 2014). Nevertheless, the flipped classroom, which prevails among educators these days, may generate the drawbacks as perceived by the students. Among others are unfamiliarity of the flipped classroom, lack of foci on watching video lectures, unclear instructions regarding in-class activities, time-consuming pre-class activities, deficiency regarding out-of-class supports, students' I.T. resources, and the difficulty of monitoring students' outside class (Lo \& Hew, 2017).

In addition to the advantages and the challenges in the implementation of the flipped classroom, previous research on the flipped classroom yields various findings in terms of facts and information about flipped classroom (Basal, 2015; Evseeva, \& Solozhenko, 2015), students' emotions and feelings of the flipped courses (Butt, 2014; Wong \& Chu, 2014), the integration of new elements into the flipped classroom (Engin, 2014, Galway, et al., 2014), and constructing design guidelines for the flipped classroom (Fraga \& Harmon, 2014). However, the flipped classroom's implementation in shaping the 21 st-century learning skills, particularly the 4Cs, while focusing on its process as well as its obstacles, is new to the development of flipped classroom theories and practice. Hence, this study aims to fill the existing gap, which is mainly concerned with the students' 4C learning skills reflected during the flipped classroom. Regarding this, the research problems are formulated as follows:

1. How does the initiation of the flipped classroom proceed?

2. What are the obstacles encountered in the implementation of the flipped classroom?

3. How are the students' $4 \mathrm{C}$ learning skills reflected in the flipped classroom?

\section{METHOD}

This study was carried out qualitatively following the procedures of conducting a lesson study. According to (Burghes \& Robinson, 2009), lesson study constitutes collaborative practice to initiate professional teaching-learning development employing the methodology of professionally practical sharing. In this regard, this study attempted to improve the learning process as realized through learning activities and experiences for the students and how the lecturer delivers the materials for the development of the teaching-learning process. Also, to attend to the nature of the lesson study, this study was done collaboratively by sharing with collaborators involved to improve the practice of teaching, particularly in implementing the flipped classroom as the primary purpose of this study.

This study was divided into three cycles, each of which began with an online classroom and ended up with the offline one. Each cycle includes two meetings where the online classroom is administered in advance of the conventional classroom. In the online classrooms, students were assigned to watch videos and to complete quizzes based upon the videos or sometimes to do the assignments for the next meeting. Besides, the assignments for the next meetings, the offline classrooms, were uploaded to Schoology as proof that the assignments are done accordingly.

To apply the flipped classroom, four lecturers were involved as collaborators in dealing with English Teaching Media subjects. Of the four collaborators, one collaborator was the lecturer teaching the subject, constituting 24 students. To record all the students' activities, several data collection techniques are deployed, encompassing observation, interviews, and the analysis of students' documents. The observation was done based on the learning process of students in the classroom and the online classroom. This was done to get some information about the learning processes, both offline and online, and record the $4 \mathrm{Cs}$. The interview was correctly administered to elicit detailed information about problems encountered during the implementation of the flipped classroom. As for the document analysis, data vis-à-vis the process, and the $4 \mathrm{C}$ realization were 
collected and then analyzed.

The analysis was done qualitatively by adhering to Interactive Model (Miles, Huberman \& Saldaña, 2014). It begins with data condensation, data display, and at last, conclusion drawing or verification where the data are interpreted. To depict the process of the flipped classroom, the data collected through observation are subject to analysis. The analysis of the data is to result in the depiction of the whole process in each cycle encompassing how materials were prepared for teaching, how students responded to the teaching materials and the learning activities, how the materials and teaching techniques are altered as the lesson study went on, and how students' learning in the Schoology was. In addition to it, the analysis of restraints in the initiation of the flipped classroom was in line with the interview data triangulated with that of the observation to provide a comprehensive interpretation of the emerging findings. Furthermore, the result of analysis for the data of 4Cs realized by the students is conveyed and presented concerning students' creativity, critical thinking, communication, and collaboration. The findings are then interpreted and associated with the existing theories for discussion.

\section{RESULTS AND DISCUSSION}

Results and discussion are presented concerning the research problems in this study. The first one is about how the initiation of the flipped classroom proceeds. It means that the process of initiating the flipped classroom is portrayed. The depiction entails the preparation of each cycle, the students' learning in the online classes, and the teacher-student interaction in the offline classes. The second one is concerned with the problems encountered during the implementation of the flipped classroom. The problems are categorized into two sections, the problems perceived by the lecturer and those experienced by the students. The last one deals with the realization of students' 4Cs in the flipped classroom. This is conveyed based upon the students' learning activities in each cycle, in the online and offline classes. Each results is then interpreted and discussed to see its relevance and relation to previous theories of the flipped classroom and the $4 \mathrm{C}$ learning skills. The detailed portrayal of each results and discussion is shown below.

\section{Results}

The results in this study are classified into three categories to address the research objectives encompassing the process of initiating flipped classrooms, the problems, and the realization of the 4 C's. The flipped classroom's implementation longed in three cycles, so the three cycles are depicted in Table 1. All the cycles were begun with an online classroom where students had to access Schoology's previous face-to-face meeting.

Table 1. Class cycles in initiating flipped classroom

\begin{tabular}{lll}
\hline Cycle & \multicolumn{1}{c}{ Class } & \multicolumn{1}{c}{ Task } \\
\hline Cycle 1 & $\begin{array}{l}\text { Prior online } \\
\text { class }\end{array}$ & $\begin{array}{l}\text { Video lecture on non-digital and digital teaching } \\
\text { media. } \\
\text { Quiz on Schoology. } \\
\text { Group assignment about videos of teaching media } \\
\text { use. }\end{array}$ \\
& Offline class & $\begin{array}{l}\text { Discussion on types of teaching media of the video } \\
\text { lecture and another video. }\end{array}$ \\
Cycle 2 & $\begin{array}{l}\text { Prior online } \\
\text { class }\end{array}$ & $\begin{array}{l}\text { Video lecture on how to implement non-digital } \\
\text { teaching media. } \\
\text { Quiz on Schoology. }\end{array}$ \\
\hline
\end{tabular}




\begin{tabular}{lll}
\hline & $\begin{array}{l}\text { Assignment to implement non-digital media in the } \\
\text { next offline class. } \\
\text { Comments on non-digital media perceived to be the } \\
\text { best. }\end{array}$ \\
Offline class & $\begin{array}{l}\text { Discussion on non-digital teaching media. } \\
\text { I am designing a lesson plan. } \\
\text { Implementation of non-digital teaching media. }\end{array}$ \\
& $\begin{array}{l}\text { Prior online } 3 \\
\text { class }\end{array}$ & $\begin{array}{l}\text { Video lecture on how to implement digital teaching } \\
\text { media. } \\
\text { Quiz on Schoology. } \\
\text { Assignment to implement digital media in the next } \\
\text { offline class. } \\
\text { Discussion on digital teaching media. } \\
\text { I am designing a lesson plan. } \\
\text { Implementation of digital teaching media. }\end{array}$ \\
\hline
\end{tabular}

In implementing the flipped classroom, there were several steps to be carried out. Following the lesson study scheme, it covers the planning, the doing, and the seeing. In planning a flipped classroom, lecturers were suggested they collaborate with other lecturers. It is beneficial, especially in designing what is needed for the course, including the lesson plan, cycles, and the materials to be added to Schoology. Since it is a lesson study, the team decided to have three cycles for the current flipped classroom. In each cycle, there are one online class and one offline class subsequently (see Mehring, 2018; Polo et al, 2018). The lecturers then create lesson plans and videos for teaching materials using screencast O'Matic, Powtoon, and video maker software. In one cycle, the lecturers provided the students with a lecturer-made video to be learned before the class meeting, one set of comprehension tests, and one topic related to learning media used for online discussion in the lecturer Schoology account.

After planning the teaching, then the lecturer practiced all the steps written in the lesson plan, namely the doing. The lecturer had taught the students to access Schoology beforehand. Besides, the students also had been given the access code of the online class on Schoology. The first online class provided two videos to be viewed and followed by some comprehension questions to be answered by the students after watching the videos. Similarly, the second and third online classes are equipped with video lectures concerning how to deploy non-digital and digital media.

Furthermore, the students were required to access the Schoology at a specific time, and they could not access the Schoology any longer if the time limit is reached. This is done for the sake of punctuality. A face-to-face meeting followed this; then, the seeing started to evaluate its application.

In the offline class, the teacher, as usual, called the attendance and checked the quiz completion on Schoology. The activities carried out in the class were discussion and sharing before the students performed and presented their work. As the offline class ended, the lecturer and the collaborators discussed what was observed and seen during the first cycle. The online class's feedback, as observed by the lecturer and for the offline class, particularly by the collaborators, was gathered for preparing the activities in the second and third cycles so that the weakness of the first cycle can be overcome. What was mended for the second and third cycles was attempting to do the test as technical errors were found and the number of video lectures uploaded, which became one video in the upcoming meetings.

Similarly, in the second and third cycles, the students were given assignments related to the materials and video lectures. They had to share ideas about how to use digital and non-digital teaching media. They have to think long and hard to find all activities possibly done by using certain teaching 
media. For instance, they listed all activities that can be applied by making use of blackboard alongside sharing ways to use it with their partners to get myriads of techniques to teach desired English skills. This activity allows students to work together as they have the same objective, although the teaching media they use might be different. Such sharing enables students to selectively choose activities that can be carried out using certain teaching media and language skills. Hence, this activity in the classroom is vital to provide students with specifically valuable information.

In addition to the process, some problems were also found as accounted for by the teachers and the students. For the teachers, the flipped classroom's stumbling blocks entailed timeconsuming preparation, the policy, and the internet connection. In the meantime, two categories of obstacles were concerned with unfamiliarity with Schoology and online classes and, again, the classic problem of connectivity. These are the results of the interview and observation.

As for the third purpose of this study regarding the realization of the $4 \mathrm{C}$ 's, all the skills comprising communication, collaboration, creativity, and critical thinking are manifested as the students engaged in the learning activities. The activities employed in the classrooms during the implementation of the flipped classroom are displayed in Table 2. Despite its prevalence of 4C among students, it is mostly observed during the offline classes, since at the beginning of the online classes the students did not fulfill some tasks assigned to them. Besides, the interaction in the online class, Schoology, is limited as the students seemed to be convenient with discussing the materials in the WhatsApp group. Some activities are shown to entail more than one skill, and letter G in the bracket denotes the group discussion.

Table 2. Activities manifesting the 4Cs skills

\begin{tabular}{|c|c|c|c|c|c|c|c|c|c|}
\hline & 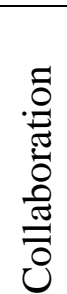 & 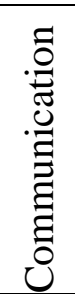 & 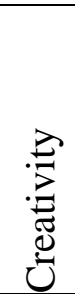 & 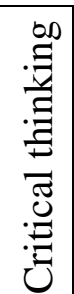 & & 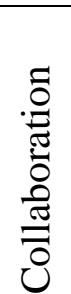 & 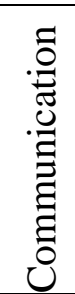 & 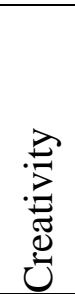 & 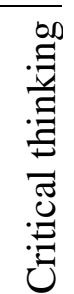 \\
\hline $\begin{array}{l}\text { Categorizing types of } \\
\text { teaching media }\end{array}$ & & $\sqrt{ }$ & & $\sqrt{ }$ & $\begin{array}{l}\text { Simulating teaching- } \\
\text { learning activities }\end{array}$ & & $\sqrt{ }$ & $\sqrt{ }$ & $\sqrt{ }$ \\
\hline Answering quizzes & & & & $\sqrt{ }$ & Working in groups & $\sqrt{ }$ & $\sqrt{ }$ & & \\
\hline $\begin{array}{l}\text { Presenting ideas in } \\
\text { discussion }\end{array}$ & & $\sqrt{ }$ & & & $\begin{array}{l}\text { Asking for clarification } \\
\text { on tasks }\end{array}$ & & $\sqrt{ }$ & & $\sqrt{ }$ \\
\hline $\begin{array}{l}\text { Discussing the benefits } \\
\text { of teaching media in } \\
\text { classrooms }\end{array}$ & $\sqrt{ }$ & $\sqrt{ }$ & & & $\begin{array}{l}\text { Providing reasons for } \\
\text { selecting specific } \\
\text { teaching media }(\mathrm{G})\end{array}$ & $\sqrt{ }$ & & & $\sqrt{ }$ \\
\hline $\begin{array}{l}\text { Summarizing types of } \\
\text { teaching media }\end{array}$ & & & & $\sqrt{ }$ & $\begin{array}{l}\text { Confirming tasks and } \\
\text { assignments }\end{array}$ & & $\sqrt{ }$ & & $\sqrt{ }$ \\
\hline $\begin{array}{l}\text { I am setting learning } \\
\text { goals for the lesson } \\
\text { plan. }\end{array}$ & & & $\sqrt{ }$ & $\sqrt{ }$ & $\begin{array}{l}\text { Comparing digital and } \\
\text { non-digital teaching } \\
\text { media (G) }\end{array}$ & $\sqrt{ }$ & & & $\sqrt{ }$ \\
\hline $\begin{array}{l}\text { Selecting appropriate } \\
\text { teaching media }\end{array}$ & & & $\sqrt{ }$ & $\sqrt{ }$ & $\begin{array}{l}\text { Preparing non-digital } \\
\text { media for teaching }\end{array}$ & & & $\sqrt{ }$ & $v$ \\
\hline $\begin{array}{l}\text { Giving comments on } \\
\text { Schoology }\end{array}$ & & $\sqrt{ }$ & & & $\begin{array}{l}\text { Preparing digital tools for } \\
\text { teaching }\end{array}$ & & & $\sqrt{ }$ & $\sqrt{ }$ \\
\hline $\begin{array}{l}\text { Designing learning } \\
\text { activities with certain } \\
\text { media }\end{array}$ & & & $\sqrt{ }$ & $\sqrt{ }$ & $\begin{array}{l}\text { Questioning is digital, } \\
\text { and non-digital teaching } \\
\text { media is appropriate. }\end{array}$ & & & & $\sqrt{ }$ \\
\hline
\end{tabular}




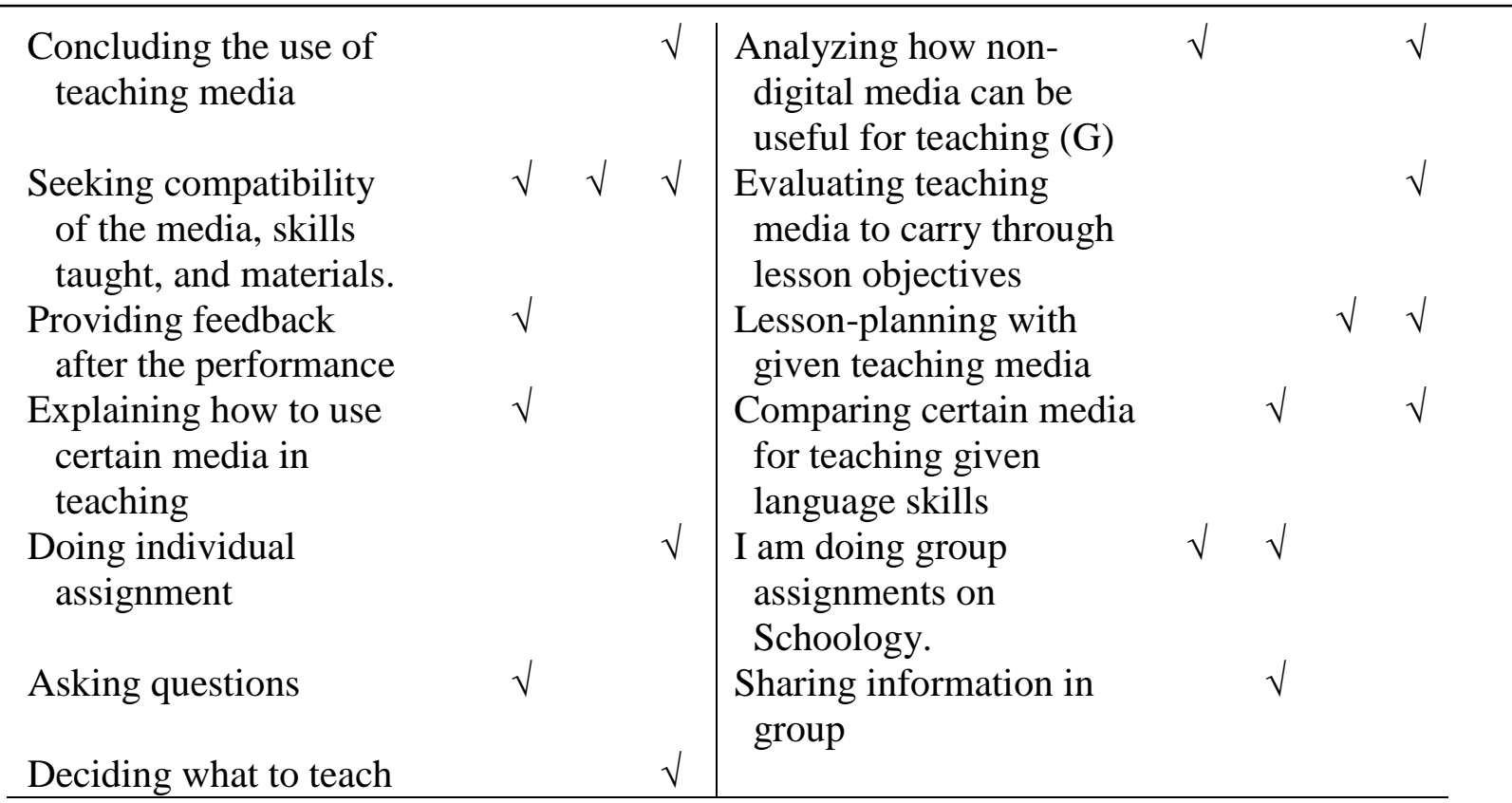

\section{Discussion}

\section{The process of initiating the flipped classroom}

In all three cycles, video lectures were used to prepare the students before coming to the class. This is based on Doman \& Webb (2016) that using video lectures in a flipped classroom is a stepthrough which the students can synthesize information and engage in the process. Besides, quizzes available in each cycle were first set to one attempt limit. Besides, once the students opened the quiz, they had to finish it all at once since they could only do it once so that the students had no time for cheating, and they had to understand the content of the video lecture. Once the quiz was opened, their attempt counted even if they returned to the main page. However, that limit was merely applied to the first cycle since the students found errors; they did the quiz, but the score did not appear. Therefore, in the next cycle, the quizzes were limited to two attempts. Allowing them to do the quiz in a limited chance can motivate them to do their best. On the contrary, an unlimited chance to finish the task results in less enthusiastic students.

The next session is face to face. The lecturer first checked the students who had not done the quiz. Some did not complete the quiz. This, as suggested by Polo et al., (2018), is one problem in the flipped classroom where some students failing to read the given materials can result in impediment of learning. As a result, those who had not done the quiz were considered absent in that meeting. This encouraged the students to do the quiz in the next meeting since the number of students finishing the quiz went up. This indicates that students in the flipped classroom can control their learning (Basal, 2015; Mehring, 2018).

After checking the quiz completion, the lecturer ascertained that the students understood the material during the online class. They were assigned a group task to build collaborative skills. The task was still related to the video the students had watched at Schoology. They were asked to share their understanding of the material in the form of a mind map. It was to enhance their critical and analytical skills, as it is stated that the face-to-face meeting in a flipped classroom is required for ideas development and sharing (Doman \& Webb, 2016; Mehring, 2018). At the end of the face-to-face session, students were assigned to present their discussion results to the class. It was to ascertain the students understood the material as well as practicing their communicative skills.

Unlike the second cycle, the third cycle focuses on the practical application of given teaching media. The implementation of particular teaching media was exemplified in the video lecture so that they could have had insights into how to do it. In the offline class, each student was assigned to teach 
particular skills such as reading, writing, listening, or speaking. The students had to consider the best way and time to use either digital or non-digital media or to combine both types of teaching media.

Furthermore, they analyzed which media would be more appropriate for teaching specific English skills since not all media could be implemented. In this cycle, the students were also asked to implement teaching media as if they were teachers properly. Hence, a holistic understanding of teaching media is required for them to teach English skills successfully. To some extent, this promotes students' skills and mental abilities transcending the existing subject matter as rethinking and idea restructuring happen to challenge them (Chu et al., 2017).

\section{The obstacles encountered in the implementation of the flipped classroom.}

The flipped classroom is considered ambiguous since the lecturers should be able to manage online and offline classes at the same time. However, the difficulty was expressed by the lecturers and the students (see Lo \& Hew, 2017). Concerning the interview with the lecturers and students, some issues emerge as the common obstacles in implementing the flipped classroom. For the lecturer, the stumbling blocks entail preparation time consumption, applied policy, and internet resources. In the meantime, the problems have to do with the familiarity and availability of connectivity for the students.

Firstly, it is time-consuming in preparation. The lecturer should allot much more time preparing the teaching media and material to be uploaded in her Schoology account, like video lectures, quizzes, and evaluation stuff. The video is one of the most time-consuming media, and it also demands the lecturer to be able to utilize video editing or presentation application such as Powtoon, Screencast O'Matic, and other video editor applications. This is also an apparent problem encountered by teachers in a previous study (see Bennett, 2013, in Mehring, 2018), including post-online class activities. It is quite troublesome when the lecturer is not really into technology to create teaching media, which requires the use of technology. Besides pedagogical knowledge, the lecturers' technological knowledge is also essential to assure the success of the flipped classroom. In other words, the ability of how to teach is not the sole property.

More importantly, the ability of how to use technology supporting the teaching preparation is the utmost importance. In this sense, the video lecture cannot be as effective and efficient as video editing is undertaken. Integrating technology necessitates technological knowledge, pedagogical knowledge, and content knowledge to yield suitable materials (Mishra \& Koehler, 2006). Knowing how to teach (pedagogy) and knowing what to teach (content) should be refined by knowing how technology is used. This is also in line with Larson \& Miller (2011) that the classrooms sensibly enriched with technology are required for students to provide them with multifaceted and varied learning experiences. For this reason, teachers in a flipped classroom are inclined to be innovative and imaginative (Wilkinson, 2016).

The second issue is the institution policy. Not all institution allows online classroom since the administration requires a certain amount of face-to-face meeting to be fulfilled in a semester. It is allowed, but then the online meeting must be made up by another offline meeting, which is inconvenient for lecturers and students. It needs more effort to convince the policymakers that online class is equal to a face-to-face meeting since the students also learn but in a different mode. This proscription is worrisome since the impact of technology in the classroom can be optimal through policymakers that make the technology, the so-called flipped classroom, possible at all costs. This is incongruous because our society's spirit to integrate technology into the classrooms, as suggested by the Ministry of Culture and Education, is getting its apex, yet the policy, in this case, happens to impede its implementation. This refers to operational challenges (Lo \& Hew, 2017), but this is different in a way that it deals with the unsupportive policy while operational challenges they proposed encompass institutional support in terms of investment in I.T. resources, teachers' I.T. skills, and monitoring.

In this case, the last issue is the facility, the internet connection provided by the institution, in a similar vein with Lo \& Hew (2017). It is a widespread and classic problem in Indonesia, especially in a 
small city in which this study was conducted. Internet connection has always been the issue when technology is being deployed in the classroom. When the lecturer checked the attendance or assignment in the Schoology, the internet connection became a hindrance, so the lecturer spent more to provide themselves with an internet connection. That was also the case in a group discussion when accessing the materials was in need. This should not have been a problem since the time available in offline class is crucial to ascertain students' comprehension and confer with the lecturer and other students so that the previous learning can be internalized and implemented in practice by them. It is affirmed that offline meeting in flipped classroom denotes a more significant element than the video lectures (Basal, 2015). Therefore, this issue's availability is likely to imperil further development of students' thinking and learning vis-à-vis the subject matter.

For the students, the flipped classroom was also a new thing. They also encountered some problems in joining it. The first problem was that they have not been familiar with the learning management system. Most of them had no problem learning the application, but it needed a few times to get used to the application. Some of them were still confused about accessing the class or submitting the assignment. In the first two meetings, the students made numerous mistakes in doing their assignments. They spent many attempts to accomplish the quiz or discussion session required by the lecturer. They used too much time for it, which should ideally be focused on face-to-face meetings (Basal, 2015). Although the students seem to be digitally capable, learning something new that is beyond their habit needs persistence, and what is more, previously, no lecturers provided them with the flipped classroom. Therefore, the lecturer's role in the flipped classroom as an orchestrator is crucial to maintain students' engagement through scaffolding in line with students' learning pace.

The next problem is similar to what the lecturer grappled with in implementing this flipped teaching. They have a problem with a limited internet connection. Some spots on campus have provided internet connection, but it was not enough to help all students access Schoology and do their assignments in the virtual classroom. Therefore, they need extra cost for internet connection as well. Even though this issue remained unsolved during the flipped classroom initiation and recurred in each cycle, almost all the students did the quizzes and the online assignments. This is observed that some students shared the connection with their classmates and even took a turn to utilize one laptop with which they did the tasks. The point is that the students made any endeavor to carry out the tasks. So, as no one is left behind, the optimal learning experience may be attained (Polo et al., 2018). This shows that a flipped classroom allows for personalized learning, meaningful learning, and feasible gain. This is asserted that a flipped classroom's deployment promotes personalized learning (Millard, 2012, in Basal, 2015; Vaughan, 2014).

As indicated above, students were given increased workload in the flipped classroom (Lo \& Hew, 2017; Mehring, 2018) as they are required to do multiple unfamiliar tasks before the class meeting. This workload can be worsened by the emerging problems found in this study. For instance, notwithstanding their engagement in learning, students are susceptible to withdrawal caused by technical issues and familiarity with the learning management system. The student can likely abandon their task before face to face classroom. Considering the facts, the materials delivered to the students in the online class, particularly in the beginning of flipped classroom, must be able to balance between what students have to do and what students have already known, not going far beyond their prior knowledge, yet challenging and sufficiently small in number. The idea is that the teacher should only deliver materials obligatory in the next meeting. Finally, as it moves to another cycle, the workload can be slightly increased. By doing so, hopefully, students can respond positively to the flipped classroom, which is in a similar vein with Butt's (2014) report that as students went through the whole session of the flipped classroom, they viewed it more positively.

If the flipped classroom is to be implemented altogether in another subject, it is suggested that the learning management system used to be the same for the sake of efficiency. It is intended to allow students to focus more on the content rather than on some technical stages. Besides, the lecturers should 
be creative in creating video lectures and other classroom activities to avoid boredom. However, creating, editing, and distributing video lectures denote dexterity beyond the teacher's reach (Whitley-Grassi \& Baizer, 2010). Hence, albeit flipped classroom as a breakthrough that enables teachers to have a closer look on the students individually, teachers are also required to develop not only pedagogical and content knowledge, but also technological knowledge as well as technological pedagogical content knowledge to result in the inappropriate practice of learning with technology.

\section{The students' 4C learning skills reflected in the flipped classroom.}

Critical thinking is realized by the students as indicated by their crucial attempts to gather relevant information, ask essential questions that help solve problems, make decisions by selecting appropriate criteria, and identify alternatives to make reliable choices. Gathering relevant information was evident when the lecturer asked students what certain media can be used to teach specific skills. This activity of gathering relevant information is perfect for fostering students' inductive and deductive reasoning if they can generalize or inferences from the information. Besides, an important question was also asked, which significantly assisted in finding a way to the given problem. This was realized when a student made sure whether the lecturer's task should include all points or only 1 point. Without such clarity on the point, the student will find it harder to do the activity, but a clear focus unleashed the difficulty.

This skill was mostly used and activated in the classroom since the lecturer facilitated the students to do so by giving a range of learning activities that required them to think critically. As depicted in the table, some activities involved not only critical thinking but also the other three skills. For instance, when the students were asked to teach one of four language skills, they chose appropriate teaching media to teach a specific skill and had to provide a reason for their selection of the media. In this activity, they had to think critically and communicate what they think to make others understand. Without these two skills, the activity can hardly be undertaken. It also needs to be noted that critical thinking was realized in individual tasks and group assignments. The ability to think critically allows for efficiency of work concerning technical and logistic issues (Polo et al., 2018).

Furthermore, students were also able to make decisions based upon some criteria, which was shown when the students were asked questions such as "what English skills will you apply based on the Basic Competence (K.D.)" and "what non-digital instructional media will you apply?". To come up with an answer, students must first think of an instructional media while considering the Basic Competence, followed by notions of how the media can be used. As they start to analyze the criteria, informed decisions can be made based on the media's considerations and what to teach. To some extent, this denotes the students' critical thinking, specifically in deductive reasoning, where the students decided based upon available premises about the functions of the instructional media and the Basic Competence to attain. This is in line with Facione et al. (1995, in Soland et al., 2013) that critical thinking entails deductive reasoning as well as making correct analyses, inferences, and evaluations.

In terms of communication skills, the students seemed to be facilitated by the learning activities to employ their communication skills, yet its execution was misleading. The skill is merely manifested in some actions carried out by the student in the classroom, such as expressing thoughts clearly and articulating opinions crisply. Other characteristics of the communication skill might have emerged if the students had done certain activities differently. Unfortunately, they failed to motivate others through persuasive speech, to communicate using digital media, to share information efficiently and effectively, and to communicate their ideas to different audiences using various media and formats.

Communication is characterized by the formation of shared knowledge and understanding vis-à-vis the topic (Polo et al., 2018). This is manifested in activities such as categorizing types of teaching media, presenting ideas in discussion, and discussing the benefits of teaching media in classrooms. The three examples of communication manifestation are concerned with how information is illuminated and shared with others. On the contrary, some of the activity has nothing to do with sharing, yet with elicitation, 
which is realized when a student asked questions and asked for clarification.

By looking at the findings, the communication skill that emerged is related to sharing ideas conventionally. It seemed that the communication skill of students in the offline classroom is partial. In other words, the students are not encouraged to use a variety of media to share their opinions or communicate their thoughts to others. However, communication is not solely about giving presentations or expressing something, yet the salient feature of communication is the consequent understanding of the audience (Bialik \& Fadel, 2015). In this regard, activities to train specific communication skills encompass peer-tutoring, active listening, thought-provoking inquiries where the acts of negotiating, giving instructions, advising, building relationships, resolving conflicts are present (ibid.). Actually, in language classes, communication skills can be easily facilitated by information gap activities.

Concerning collaboration, the provision of learning activities in which the students were required to work in a group to pursue a common goal to specific extent results in this skill realization. Collaboration is one of the interpersonal competencies alongside communication required in the 21 st century (Soland et al., 2013). In this sense, the students worked together effectively to accomplish a shared, common goal, they did compromise relentlessly, demonstrated some degree of responsibility and participated as members of a group to attain the shared goal. This indicates that the students are accustomed to practicing their collaboration skills. They did not appear to be worried about doing the activities in the group. This shows the students' emerging capacity to work in harmony with others on behalf of the given goal.

Notwithstanding their familiarity with collaboration skills, the students did not demonstrate the skills of negotiation. Negotiation is deemed paramount in any collaborative situation (Alber, 2012, in Soland et al., 2013). This is sensible since, in negotiation, articulating points of agreement while thinking clearly under pressure is not easy. The students are supposed to have the negotiation skills to solve multifaceted problems with the aid of people with diverse skills and backgrounds and to be competitive in a world of increasing complexity.

Among others, this skill is the least used skill in the activity. About this, it is affirmed that collaboration is connected to communication because to be able to collaborate requires communication (Polo et al., 2018). This indicates that the students can only collaborate if facilitated by the lecturer, especially in group work or assignments, yet they could not build collaboration. Therefore, teachers should provide them with a myriad of activities that lead to students' collaboration because a lack of collaboration might bring about the difficulty for them accordingly. The practical implication that teachers can do is to set standards and shared goals for students to attain.

Regarding creativity, it is apparent that the students performed a certain extent of creativity skill. However, their realization of creativity is restricted to some modification or elaboration on the subject discussed. What is missing is their ability to produce novel ideas independent of previous materials given to them. This was observed when the students discussed non-digital media, and then they combined two learning media for teaching, yet the use of those media was just the same as what is exemplified in the video lecture. This could be caused by their tendency to effectively reach the lesson's objective rather than innovatively using the media for different purposes, which might lead to the failure to achieve lesson objectives.

It should be noted that the extent to which the students employed their creativity skill, to follow Bialik \& Fadel (2015), is at the Combination level, which is defined as mixture two or more works into one. In this regard, the students combine two learning media for teaching specific skills. The combination becomes a perfect mixture to teach the skills with the given objectives of the lesson. However, students' two more levels of creativity should be pursued if challenges in the new digital age of the 21 st century, which are the transformation and original creation levels (ibid.). Albeit the limitation of their creativity, their emerging capacity of creativity can appropriately choose teaching media for teaching language skills, which can barely occur without creativity. Besides, creativity constitutes an opaque and hard skill 
to tick due to the nature of the process (Polo et al., 2018).

As the use of flipped classroom can realize the 4C learning skills, it is worth implementing. This can be chosen to prepare students to be fully equipped to face the intricacy of the disruptive era. Besides, it is also indicated in the findings that communication is concerned with collaboration. The opportunity to collaborate can be enhanced by as much as possible, enabling students to communicate online and faceto-face. Furthermore, critical thinking is associated with creativity in that many activities requiring critical thinking demand creativity to be able to get the objectives of the lesson. This results from the nature of learning activities deployed and designed by the lecturer. Finally, the higher number of activities employed in offline classes bear out the significance of online classes whose assignment should be done entirely; otherwise, students nearly cannot catch up and engage in the activities.

\section{CONCLUSION}

The flipped classroom is considered suitable as the teaching approach for the future when the students are no longer required to attend class face-to-face. They could learn anytime as long as they are connected to the internet. This lesson study has given broader insight into the implementation of Schoology in building pre-service teachers' 4Cs. The results showed that, in initiating a flipped class, the lecturers should work hard to provide students with creative video lectures and other classroom activities. As for the last issue, the findings reveal that the students showed their 4Cs during online and offline classes, starting with creativity, collaboration, critical thinking, and communication. Flipped classroom constitutes a breakthrough that allows for looking over every individual. However, since it is a new method, the flipped classroom is considered too intricate, since the time allotment for preparing the materials needs to be long enough. This study recommends that the flipped classroom be applied in pre-service teachers' higher education since it is very beneficial to build the 21 st-century skills that would be beneficial for them to pursue their future jobs as teachers and other professions.

\section{REFERENCES}

Basal, A. (2015). The implementation of a flipped classroom in foreign language teaching. Turkish Online Journal of Distance Education, 16(4), pp. 28-37.

Bialik, M. and Fadel, C. (2015). Skills for the 21st century: what should students learn?. Boston: C.C.R.

Burghes, D. and Robinson, B. (2009) Lesson study: enhancing Mathematics teaching and learning. Plymouth: CfBT.

Butt, A. (2014). Student views on the use of a flipped-classroom approach: evidence from Australia. Business Education \& Accreditation, 6(1), pp. 33-44.

The Chu, S.K.W. et al. (2017). $21^{\text {st }}$-century skills development through inquiry-based learning. Singapore: Springer Science+Business Media Singapore. DOI 10.1007/978-981-10-24818_4

Dede, C. (2010). Comparing frameworks for 21st-century skills. In J. Bellanca \& R. Brandt (Eds.), 21st Century Skills: Rethinking How Students Learn (pp. 51-75). Bloomington: Solution Tree Press.

Doman, E., and Webb, M. (2016). The flipped experience for Chinese university students studying English as a foreign language. TESOL Journal of 2016. Doi: 10.1002/tesj.264

Evseeva, A., and Solozhenko, A. (2015). Use of flipped classroom technology in language learning. Procedia - Social and Behavioral Sciences, 206(2015), pp. 205 - 209.

Engin, M. (2014). Extending the flipped classroom model: developing second language writing skills through student-created digital videos. Journal of the Scholarship of Teaching and Learning, 14(5), pp. 12 - 26. DOI: 10.14434/josotlv14i5.12829 
Fraga, L. M., and Harmon. J. (2014). The flipped classroom model of learning in higher education: an Investigation of Preservice Teachers' Perspectives and Achievement. Journal of Digital Learning in Teacher Education, 31(1), pp. 18-27. DOI:10.1080/21532974.2014.967420

Galway, L. P., Corbett, K. K., Takaro, T. K., Tairyan, K., and Frank, E. (2014). A novel integration of online and flipped classroom instructional models in public health higher education. B.M.C. Medical Education, 14(181), pp. 1-9.

Larson, L. C., and Miller, T. N. (2011). $21^{\text {st }}$-century skills: prepare students for the future. Kappa Delta Pi Record, 47(3), pp.121-123. DOI: 10.1080/00228958.2011.10516575

Lo, C. K., and Hew, K. F. (2017). A critical review of flipped classroom challenges in K-12 education: possible solutions and recommendations for future research. Research and Practice in Technology Enhanced Learning, 12(4), pp.1-22. DOI:10.1186/s41039-016-00442

Mehring, J. (2018). The flipped classroom. in Mehring, J., \& Leis, A.(Eds.). (2018). Innovations in flipping the language classroom: theories and practice. New York: Springer Nature Singapore. https://doi.org/10.1007/978-981-10-6968-0_1

Miles, M.B., Huberman, A.M. and Saldaña, J. (2014). Qualitative data analysis: a methods sourcebook. London: Sage.

Mishra, P., and Koehler, M. J. (2006). Technological pedagogical content knowledge: a new framework for teacher knowledge. Teachers College Record. 108(6), 1017-1054.

O'Flaherty, J., and Phillips, C. (2015). The use of flipped classrooms in higher education: a scoping review. Internet and Higher Education, 25(2015), pp. 85-95. Doi: http://dx.doi.org/10.1016/j.iheduc.2015.02.002

Polo, B. J., Silva. P. A., and Crosby, M. E. (2018). Applying studio-based learning methodology in computer science education to improve 21 st-century skills. In Zaphiris, P., \& Ioannou, A.(Eds.). Learning Collaboration and Technology 2018, LNCS 10925, pp. 361-375, Las Vegas: Springer International Publishing. https://doi.org/10.1007/978-3-319-91152-6_28

Soland, J., Hamilton, L. S., and Stecher, B. M. (2013). Measuring 21st-century competencies: guidance for educators. Los Angeles, CA: Asia Society/Rand Corp.

Van Laar, E., van Deursen, A.J.A.M., van Dijk, J.A.G.M., and de Haan, J. (2017). The relation between 21 st-century skills and digital skills or literacy: a systematic literature review. Computers in Human Behavior (2017). DOI: 10.1016/j.chb.2017.03.010

Vaughan, M. (2014). Flipping the learning: an investigation into the flipped classroom model's use in an introductory teaching course. Educational Research and Perspective, 41(2014), pp. 2541.

Whitley-Grassi, N., and Baizer, J. S. (2010). Video lecture capture in physiology courses: student attendance, video viewing, and correlations to course performance. International Journal of Instructional Technology and Distance Learning, 7(10), 31-38.

Wilkinson, M. (2016). Language learning with I.C.T. In Renandya, W. A., Widodo J. P. (eds.). (2016). English language teaching today, English Language Education 5. DOI: 10.1007/9783-319-38834- -2_18.

Wong, K., and Chu, D. W. K. (2014) Is the flipped classroom model effective in students' perceptions and benefits? Cheung, S.K.S. et al. (Eds.). I.C.H.L., 2014, pp. 93-104. Doi:10.1007/978-3-319-08961-4_10 